University of Wollongong

Research Online

Australian Institute for Innovative Materials -

Papers

Australian Institute for Innovative Materials

2013

\title{
Cell attachment and proliferation on high conductivity PEDOT-glycol composites produced by vapour phase polymerisation
}

\author{
Elise M. Stewart \\ University of Wollongong, elises@uow.edu.au \\ Manrico Fabretto \\ University of South Australia \\ Mischa Mueller \\ University of South Australia \\ Paul J. Molino \\ University of Wollongong, pmolino@uow.edu.au \\ Hans J. Griesser \\ University of South Australia
}

See next page for additional authors

Follow this and additional works at: https://ro.uow.edu.au/aiimpapers

Part of the Engineering Commons, and the Physical Sciences and Mathematics Commons

Research Online is the open access institutional repository for the University of Wollongong. For further information contact the UOW Library: research-pubs@uow.edu.au 


\title{
Cell attachment and proliferation on high conductivity PEDOT-glycol composites produced by vapour phase polymerisation
}

\begin{abstract}
High conductivity poly(3,4-ethylene dioxythiophene) (PEDOT) was synthesised using vacuum vapour phase polymerization (VVPP). The process produces PEDOT composites which incorporate glycol within the polymer. To assess biocompatibility, a suite of analytical techniques were utilised in an effort to characterise the level of glycol present and its impact on cell attachment and proliferation. A small decrease in fibroblast cell attachment and proliferation was observed with increasing glycol content within the PEDOT composite. Keratinocyte cell attachment and proliferation by comparison showed an increase. As such, the results herein indicate that cell attachment and proliferation depends on the individual cell lines used and that the impact of glycol within the PEDOT composite is negligible. This positive outcome prompted investigation of this polymer as a platform for electro-stimulation work. Application of oxidising and reducing potentials to the PEDOT composite were utilised to examine the effect on biocompatibility. Significant effects were seen with altered protein presentation on the reduced surface, and lower mass adsorbed at the oxidised surface. Keratinocytes interacted significantly better on the reduced surface whereas fibroblasts displayed dependence on protein density, with significantly lower spreading on the oxidised surface. Understanding how proteins interact at electrically biased polymer surfaces and in turn affect cell behaviour, underpins the utilisation of such tunable surfaces in biomedical devices.
\end{abstract}

\section{Keywords}

pedot, conductivity, high, proliferation, attachment, cell, glycol, composites, produced, vapour, phase, polymerisation

Disciplines

Engineering | Physical Sciences and Mathematics

\section{Publication Details}

Stewart, E. M., Fabretto, M., Mueller, M., Molino, P. J., Griesser, H. J., Short, R. D. \& Wallace, G. G. (2013). Cell attachment and proliferation on high conductivity PEDOT-glycol composites produced by vapour phase polymerisation. Biomaterials Science, 1 (4), 368-378.

\section{Authors}

Elise M. Stewart, Manrico Fabretto, Mischa Mueller, Paul J. Molino, Hans J. Griesser, Robert D. Short, and Gordon G. Wallace 


\title{
Cell attachment and proliferation on high conductivity PEDOT-glycol composites produced by vapour phase polymerisation
}

Elise M. Stewart, ${ }^{1}$ Manrico Fabretto, ${ }^{2,3^{*}}$ Mischa Mueller, ${ }^{3}$ Paul J. Molino, ${ }^{1}$ Hans J. Griesser, ${ }^{2}$ Robert D. Short, ${ }^{3}$ Gordon G. Wallace ${ }^{1 *}$

${ }^{1}$ Intelligent Polymer Research Institute, Innovation Campus, University of Wollongong, NSW, 2522, Australia

${ }^{2}$ Ian Wark Research Institute, University of South Australia, Mawson Lakes, SA, 5095, Australia

${ }^{3}$ Mawson Institute, University of South Australia, Mawson Lakes, SA, 5095, Australia

${ }^{*}$ Corresponding authors: Materials- email: rick.fabretto@unisa.edu.au

Bio-email: gwallace@uow.edu.au

\begin{abstract}
:
High conductivity poly(3,4-ethylene dioxythiophene) (PEDOT) was synthesised using vacuum vapour phase polymerization (VVPP). The process produces PEDOT composites which incorporate glycol within the polymer. To assess biocompatibility, a suite of analytical techniques were utilised in an effort to characterise the level of glycol present and its impact on cell attachment and proliferation. A small decrease in fibroblast cell attachment and proliferation was observed with increasing glycol content within the PEDOT composite. Keratinocyte cell attachment and proliferation by comparison showed an increase. As such, the results herein indicate that cell attachment and proliferation depends on the individual cell lines used and that the impact of glycol within the PEDOT composite is negligible. This positive outcome prompted investigation of this polymer as a platform for electro-stimulation work. Application of oxidising
\end{abstract}


and reducing potentials to the PEDOT composite were utilised to examine the effect on biocompatibility. Significant effects were seen with altered protein presentation on the reduced surface, and lower mass adsorbed at the oxidised surface. Keratinocytes interacted significantly better on the reduced surface whereas fibroblasts displayed dependence on protein density, with significantly lower spreading on the oxidised surface. Understanding how proteins interact at electrically biased polymer surfaces and in turn affect cell behaviour, underpins the utilisation of such tuneable surfaces in biomedical devices.

Keywords: Vacuum vapour phase polymerisation (VVPP); PEDOT; electrical stimulation; cell spreading; Quartz crystal microbalance (QCM) 


\section{Introduction}

The use of inherently conducting polymers (ICPs) as an alternative to traditional metallic materials for charge transport has, in recent times, seen these materials subjected to intense investigation. Of the many conducting polymers that have been synthesised and studied, poly(3,4-ethylenedioxythiophene) (PEDOT) is arguably one of the most highly conductive and environmentally stable[1-4]. The facile manner in which PEDOT can be synthesised using a variety of protocols, such as wet chemical oxidation, electrochemical polymerisation or vapour phase polymerisation (VPP), has resulted in it becoming one of the most commonly used ICPs. Importantly the energetic state of the surface, the conductivity and the optical transmission of PEDOT can be altered by changing the doping level within the polymer. This can be achieved either by electrical or chemical means and exploiting this phenomenon has resulted in a plethora of potential applications such as power storage and generation[5], organic transistors (OFETs)[6, 7], and drug delivery devices, bioactive-platforms and biosensors[8].

For biological applications, such as tissue engineering, it is important to create a structure or scaffold that provides physical and/or chemical support conducive to interactions between the substrate and cells, as well as between neighbouring cells.[9-11] As such, the surface properties of biomaterials are critically important in that they determine the nature of interactions with cells via the protein mediators of such interactions.[12] Modification of the conducting polymer surface properties can be effected by altering the polymer composition[13], surface roughness[14], the type of dopant[15], and the doping level[16], as well as the redox state of the polymer.[15] Each of these properties has been shown to affect cell behaviour.[17-20] Furthermore, the application of electrical stimuli has long been known to influence the manner in which nerves,[21] cartilage[22], skin tissue[23] and bone[24] heal. Therefore, careful manipulation of these physical, chemical or electrical cues has the potential to influence cell behaviour in some desired manner.

While numerous bio-compatibility studies have been performed on polypyrrole[25-28] and to a lesser extent PEDOT[29, 30], interestingly, a survey of the current literature revealed no 
bio-material studies with VPP PEDOT. Previous studies[31, 32] have shown that the

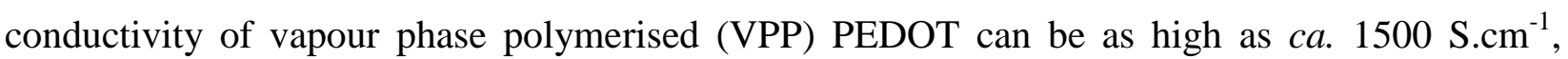
which is only one order of magnitude smaller than some metals or alloys. Such a result opens up the possibility of using VPP PEDOT as both the bio-platform and the electrode material for use in electrically active devices. One of the most commonly used oxidants in the VPP process is Fe(III) Tosylate; however, its use is not without problems. Due to its high (apparent) reactivity, PEDOT films having poor conductivity due to conjugation defects have been reported[33]. To overcome this problem, various methods have been employed to reduce the (apparent) reactivity of the oxidant. One method utilises a glycol based surfactant as a means of reducing the reactivity of the oxidant solution via a steric hindrance mechanism[34]. The consequence of using glycol, however, is that a PEDOT/glycol composite is formed during polymer synthesis[32]. Even though glycol on a biomaterial surface is known to inhibit the attachment of proteins and cells[35, 36], and is at odds with the general requirements for most tissue engineering applications, the possibility of utilising such a high conductivity polymer for electrically stimulated cell studies would seem to be highly desirable. The effect of glycol on protein adsorption and cell adhesion is dependent on the molecular weight and distribution (i.e. surface density) present on the surface, as it is generally attributed to being a steric hindrance phenomenon[37, 38]. Previous studies[39-41] using various glycols have either coated the entire substrate in an effort to inhibit cell attachment, or have patterned the surface in some manner in an attempt to produce directed/preferential cell attachment and proliferation. Irrespective of the desired outcome being sought, these previous studies have coated glycol onto the respective substrates. To the best of our knowledge, biological studies have not been performed with polymers containing glycol inherently within the polymer matrix, rather they have simply being adsorbed onto the surface. An interesting question is whether incorporated glycol produces, by its inherent surfactant activity, a surface concentration high enough to affect cell attachment and spreading.

One of the first steps in establishing the suitability of a new material for bio-engineering purposes is to confirm its biocompatibility using in vitro tests with a variety of cell types. As stated, previous studies with different cells have shown that PEDOT is indeed capable of supporting cell attachment and proliferation. This study outlines the synthesis of ultra-high 
conductivity PEDOT using the VPP technique, and its fabrication into thin films suitable for invitro use. Furthermore, a suite of surface characterisation techniques were employed in an effort to elucidate the manner in which glycol is incorporated into the PEDOT polymer composite. Our results indicate that the incorporation of glycol has minimal impact on cell attachment and proliferation. The conducting nature of the polymer was also exploited to examine the effects of applying oxidising or reducing potentials on the adsorption of proteins and cell behaviour on this biased surface.

\section{Materials and methods}

\subsection{Materials}

Fe(III) Tosylate $\left(\mathrm{Fe}(\mathrm{Tos})_{3}\right)$ was purchased from H. C. Starck as a 40 wt.-\% solution in butanol (Baytron CB 40). 3,4-ethylenedioxythiophene (EDOT) monomer and the tri-block polymer poly(ethylene glycol-propylene glycol-ethylene glycol) (PEG-PPG-PEG, referred to as 'glycol'), $M w=2900 \mathrm{Da}$. were obtained from Aldrich. Tris base, ethylenediaminetetraacetic acid (EDTA), Triton X-100 and phosphate buffered saline (PBS) tablets were purchased from Sigma. Dulbecco's Modified Eagles Medium (DMEM), Fetal Bovine Serum (FBS), Trypsin-EDTA, QuantIt Pico-Green Reagent, Phalloidin-Alexa 488, 4',6-diamidino-2-phenylindole (DAPI) and human plasma fibronectin (Fn) were purchased from Invitrogen. All chemicals were used as received.

\subsection{Vacuum Vapour Phase Polymerisation of PEDOT}

PEDOT samples were synthesised on glass microscope slides. The slides were washed using a mild detergent, followed by an ethanol and high purity water rinse. Prior to spinning the oxidant the substrates were air plasma treated (PDC-32G, Harrick Inc.) for 2 min. The 40 wt.-\% $\mathrm{Fe}(\mathrm{Tos})_{3}$ solution was further diluted with butanol to produce either a 16 or 26.6 wt.\% solution. Glycol in the weight range 0 to 65 wt.-\% (with respect to $\mathrm{Fe}(\mathrm{Tos})_{3}$ ) was then added to the oxidant solution. The solution was spin-coated (400B-6NPP, Laurell Technologies Inc.) at a speed of 1900 RPM for 20 seconds and placed on a $70{ }^{\circ} \mathrm{C}$ hot plate for 1 minute to evaporate the butanol. Samples were removed from the hotplate and immediately placed into a $115 \mathrm{~L}$ vacuum chamber oven (Binder, Germany) set to $35{ }^{\circ} \mathrm{C}$. The chamber was pumped down to 45 mbar before 
allowing EDOT monomer and water vapour ingress. Samples were removed after 25 min and placed on a $70{ }^{\circ} \mathrm{C}$ hotplate for $2 \mathrm{~min}$ to anneal the polymer. The sample was then carefully rinsed in an ethanol bath to remove the spent oxidant.

\subsection{X-Ray Photoelectron Spectroscopy}

X-ray photoelectron spectroscopy (XPS) was performed using a Kratos AXIS Ultra DLD spectrometer, using monochromatic $\mathrm{AlK}_{\alpha}$ radiation $(h v=1486.7 \mathrm{eV})$. The unit is equipped with a magnetically confined charge compensation system. Spectra were recorded using an acceleration voltage of $15 \mathrm{keV}$ at a power of $225 \mathrm{~W}$.

Survey spectra were collected with a pass energy of $160 \mathrm{eV}$ and the analysis area was $300 \times 700 \mu \mathrm{m}$. High-resolution spectra were obtained using a $20 \mathrm{eV}$ pass energy and an analysis

area of $\approx 300700 \mu \mathrm{m}$. Data analysis was performed using CasaXPS software (Casa Software $\mathrm{Ltd})$. All binding energies were referenced to the low energy C1s peak at $285.0 \mathrm{eV}$. Core level envelopes were curve-fitted with the minimum number of mixed Gaussian-Lorentzian component profiles. Curve fitting was performed with a Gaussian-Lorentzian mixing ratio (typically 30\% Lorentzian and 70\% Gaussian functions), and the full width at half maximum and the positions and intensities of the peaks unconstrained.

\subsection{Time-of-Flight Secondary Ion Mass Spectrometry}

ToF-SIMS analyses were performed with a PHI TRIFT V nanoTOF instrument (PHI Electronics Ltd, USA). A $30 \mathrm{keV}$, pulsed primary ${ }^{197} \mathrm{Au}^{+}$ion beam was used to sputter and ionise species from each sample surface. Spectra were acquired for 60 seconds from an area of $100 \times$ $100 \mu \mathrm{m}$. The corresponding total primary ion fluence was less than $1 \times 10^{12}$ ions per $\mathrm{cm}^{2}$ (operating within the static SIMS regime [1]). A dual beam charge neutralization system using a combination of low energy ions $(\leq 10 \mathrm{eV})$ and electrons $(\leq 25 \mathrm{eV})$ was employed to provide improved charge neutralisation. Mass axis calibration was performed with $\mathrm{CH}_{3}{ }^{+}, \mathrm{C}_{2} \mathrm{H}_{5}{ }^{+}$and $\mathrm{C}_{3} \mathrm{H}_{7}{ }^{+}$in positive mode and $\mathrm{CH}^{-}, \mathrm{C}_{2} \mathrm{H}^{-}$and $\mathrm{Cl}^{-}$in negative mode. A mass resolution of $\mathrm{m} / \Delta \mathrm{m}>$ 7000 at nominal $\mathrm{m} / \mathrm{z}=27 \mathrm{amu}\left(\mathrm{C}_{2} \mathrm{H}_{3}{ }^{+}\right)$was achieved. 


\subsection{Conductivity}

Resistivity, R, ( Rulas measured using a four-point probe (RM3, Jandel Engineering), tip radius $100 \mu \mathrm{m}, 60 \mathrm{~g}$ preset load and measurements were taken at room temperature (22 \pm 2 $\left.{ }^{\circ} \mathrm{C}\right)$ and humidity $(35 \% \pm 5 \%)$. Results are the average of at least nine measurements. AFM images and measurements (NTEGRA, NT-MDT) were performed in tapping mode. Polymer film thickness, $t$, was measured by carefully scoring the surface using a soft scalpel and performing line scans across the groove. Reported thickness is the average of at least 4 line scans. PEDOT conductivity, $\sigma,\left({\mathrm{S} . \mathrm{cm}^{-1}}^{-1}\right)$ is given by ;

$$
\sigma=1 /(R \times t)
$$

\subsection{Contact angle goniometry measurements}

Contact angle measurements were performed on a custom made goniometer. Droplet shapes were recorded with a M-852 colour CCD camera attached to an Olympus SZ-PT stereomicroscope. Droplet shapes were analysed using the drop snake software.[42] The advancing contact angle was recorded by slowly increasing the drop volume and ensuring that the contact line was not "pinned” by any chemical or physical defect. The advancing contact line was halted and then an image captured after 3 seconds. The receding contact angle was recorded by allowing the drop to evaporate and waiting until the contact line transitioned from an advancing state to a receding state, allowing the contact line to move freely. Care was taken to ensure that the receding contact line did not exhibit any "pinning” prior to capturing the image used to calculate the contact angle. The results are the average of at least 5 captured images and use both the right and left contact lines of the drop. 


\subsection{Atomic Force Microscopy}

PEDOT film roughness measurements (RMS) were performed by scanning the surface with an atomic force microscope (NTEGRA, NT-MDT). Scans were performed over two length scales (area of $100 \mu^{2}$ and $1 \mu^{2}$ ) at a scan speed of $1 \mathrm{~Hz}$. The root mean square (RMS) roughness values were calculated using the NT-MDT image analysis software.

\subsection{Protein Adsorption}

Static Protein Adsorption: $\quad$ PEDOT was synthesised as previously described onto piranha cleaned gold coated quartz crystal microbalance (QCM) crystals. AFM scans were performed on each sample to determine surface area of coated QCM sensors utilising an MFP-3D ARM (Asylum Research, CA). Scans (5 x $5 \mu \mathrm{m}$ ) were undertaken and surface area and RMS roughness were quantified to compare between PEDOT samples. Samples were hydrated in PBS until stable $f$ and $D$ measurements were obtained. The samples were then exposed to fibronectin at $50 \mu \mathrm{g} / \mathrm{mL}$ for $1 \mathrm{~h}$, followed by rinsing with PBS until consistent $f$ and $D$ measurements were observed. The Q-tools software package v.3.0.10.286 (Biolin Sci, AB) was used to apply the Voigt model to determine the mass $\left(\mathrm{ng} / \mathrm{cm}^{2}\right)$ of protein adsorbed to the modified sensor surface, using specific input parameters that provided the best data fit for the layer density $\left(1150 \mathrm{~kg} / \mathrm{m}^{3}\right)$, fluid density $\left(1020 \mathrm{~kg} / \mathrm{m}^{3}\right)$, layer viscosity $\left(1^{-6} \leq 1^{-2} \mathrm{~kg} / \mathrm{ms}\right)$, layer shear modulus $\left(1^{4} \leq 1^{7} \mathrm{~Pa}\right)$, and mass $\left(115 \leq 1.15^{5} \mathrm{ng} / \mathrm{cm}^{2}\right)$. The $5^{\text {th }}$ overtone was used for all modelling calculations.

Biased Protein Adsorption: QCM crystals coated with PEDOT synthesised with 48 wt.\% glycol were loaded into a QSense Electrochemistry module and the same method as above was employed to obtain hydrated PEDOT films. The Electrochemistry module consists of a platinum counter-electrode acting as the top wall of the chamber above the sensor and an $\mathrm{Ag} \mid \mathrm{AgCl}$ reference electrode included in the outlet flow channel. Samples were then stimulated with a nominated voltage (+/- $100 \mathrm{mV}$, slightly oxidising/reducing; or $+/-300 \mathrm{mV}$, strongly oxidising/reducing; vs. Ag|AgCl reference) using an eDAQ potentiostat until stable $f$ and $D$ measurements were observed (approx. $15 \mathrm{~min})$. Fibronectin $(50 \mu \mathrm{g} / \mathrm{mL})$ was then applied to the samples followed by rinsing with PBS until consistent $f$ and $D$ measurements were observed. 


\subsection{Cell Culture}

Mouse fibroblast (3T3) and human keratinocyte (HaCaT) cell lines, were originally sourced from the ATCC (American Type Culture Collection) and were used as models for epidermal cell types. Each cell type was cultured in DMEM (Dulbecco's Modified Eagle’s Medium, Invitrogen, Sydney, Australia) containing $4 \mathrm{mM}$ L-glutamine and 10\% Fetal Bovine Serum (FBS). Cells were cultured at $37^{\circ} \mathrm{C}$ in a humidified, $5 \% \mathrm{CO}_{2}$ atmosphere and were subcultured twice weekly.

\subsection{Cell Adhesion and Proliferation on VPP PEDOT}

Static Cell Culture: Prior to cell seeding onto each material, surfaces were rinsed with $70 \% \mathrm{EtOH}$ and allowed to air dry in a sterile environment. Materials were then soaked in DMEM for $1 \mathrm{~h}$, the media removed and cells seeded at a density of 4000 cells $/ \mathrm{cm}^{2}$ on each substrate. Cells were then incubated in a humidified $37^{\circ} \mathrm{C}$ incubator with $5 \% \mathrm{CO}_{2}$ atmosphere with media changes every $48 \mathrm{~h}$. Following cell incubation on polymers the medium was removed and cells were rinsed with PBS to remove loosely bound cells. Cells were then incubated with Tris/EDTA buffer (10 mM Tris, 1 mM EDTA) containing 0.5\% Triton X-100 for 10 min at room temperature followed by collection of cell lysate. DNA content was quantified using QuantIt PicoGreen reagent, and compared against standard cell numbers to quantify cell numbers at each time point. Experiments were performed in quadruplicate on at least two separate batches of polymer. GraphPad Prism 4 was utilized to determine statistical differences between net fluorescence measurements observed at specific timepoints using a 1-way ANOVA at a 95\% confidence interval.

To quantify the metabolic activity of cells attached to the polymers at various times, unbound cells were removed, and polymers/cells washed twice in serum free media before cell number was quantified using the CytoTox96 ${ }^{\mathrm{TM}} \mathrm{LDH}$ Assay Kit (Promega) according to manufacturer's specifications. Cell lysate was incubated with assay reagent for $30 \mathrm{~min}$ at room temperature, before the reaction was stopped. Absorbance measurements (adjusted for background) were taken at $490 \mathrm{~nm}$ using a SpectraMax 190 (Molecular Devices). 
Biased Cell Culture: To evaluate the effect of differences in protein layer properties on the adhesion of cells to PEDOT surfaces, substrate samples synthesised on glass slides were treated as follows. Samples were sterilised in $70 \%(\mathrm{v} / \mathrm{v}) \mathrm{EtOH}$, hydrated in PBS for $2 \mathrm{~h}$ prior to application of a nominated voltage using an eDAQ potentiostat for 15 min. Complete media containing serum was then applied to the samples for 30 minutes prior to cell seeding at a density of 15,000 cells $/ \mathrm{cm}^{2}$. Samples were placed into a humidified $37^{\circ} \mathrm{C}$ incubator with $5 \% \mathrm{CO}_{2}$ atmosphere for $12 \mathrm{~h}$ prior to application of CalceinAM (1/200 dilution in culture media) and a further 15 min incubation. Media was then removed and replaced with PBS prior to imaging using an AxioImager microscope fitted with an AxioCAM Mrm camera. Average cell area per cell body was then calculated using ImageJ software and compared between bias conditions.

\subsection{Immunocytochemistry}

Cell morphology was investigated on the polymers at different time points following cell incubation on each substrate as described above. Cells were rinsed twice in PBS to remove unbound cells, then fixed using 50\% (v/v) methanol:acetone for $5 \mathrm{~min}$ on ice, followed by two subsequent PBS washes. Samples were then incubated with the actin stain Phalloidin-Alexa 488 (diluted 1:200 in PBS/1\% BSA) for 20 min at room temperature in the dark, rinsed twice in PBS, and incubated with $1 \mu \mathrm{g} / \mathrm{mL}$ 4',6-diamidino-2-phenylindole (DAPI) in PBS for 5 min at room temperature in the dark. Solutions were removed and replaced with fresh PBS then imaged using an AxioImager microscope fitted with an AxioCAM Mrm camera and overlayed using AxioVison 4 software (Zeiss).

\section{Results}

\subsection{Vapour Phase Polymerisation and PEDOT conductivity}

The goal was to produce PEDOT having as high a conductivity value as possible, with the aim being to utilise this substrate in electro-stimulation cell work. With this in mind a series of VPP PEDOT films were synthesised by systematically increasing the amount of PEG-PPG-PEG (glycol surfactant) in the oxidant solution from 0 to $65 \mathrm{wt} . \mathrm{\%} \%$. Given that the oxidant is spin-cast onto the substrate and then dried on a hot plate to remove unbound solvent, the glycol content presented in Figure 1 is given as a weight percent of the dry-oxidant layer, rather than as a weight 
percent of the original solution. With no glycol addition, the conductivity of the PEDOT film

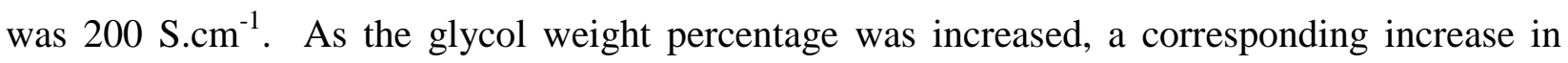
conductivity was recorded, with a maximum conductivity of $1486{\mathrm{~S} . \mathrm{cm}^{-1}}^{-1}$ being achieved at a glycol loading of 48 wt.-\%. Increasing the weight percentage beyond this level resulted in decreased conductivity, with 783 S.cm ${ }^{-1}$ being recorded at the highest loading of 65 wt.-\%. The rationale for pursuing high conductivity PEDOT as a bio-compatible material is that the polymer could serve as an effective electrode biomaterial for electro-stimulation cell work, a feature which has received an increased level of investigation.[43, 44] To ascertain whether any of the glycol that is contained within the oxidant layer becomes embedded in the synthesised PEDOT polymer, a combination of analytical techniques were used.

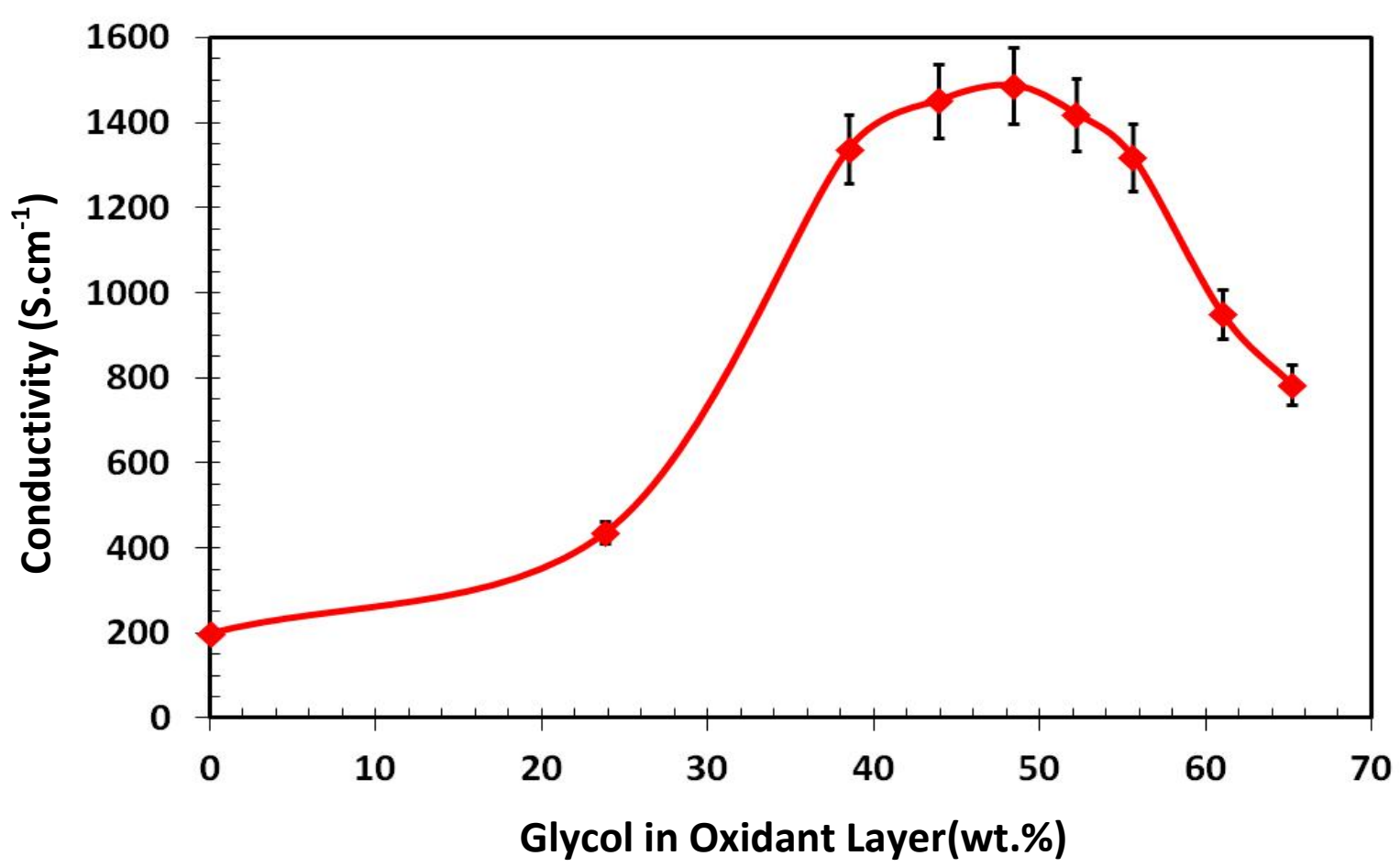

Figure 1. VPP PEDOT conductivity as a function of weight percentage of the glycol surfactant within the oxidant layer. (Glycol content within PEDOT capped at 16 wt.\%, See Fig. 2) 


\subsection{XPS analysis of VPP PEDOT}

Surface located glycol is known to have detrimental effects on cell attachment and proliferation. Previous work[45] synthesising PEDOT had indicated that using oxidant solutions with glycol additives resulted in films that contained glycol, in effect producing a PEDOT-glycol composite material. This being the case it was of paramount importance to quantify the amount of glycol present and its distribution and domain sizes. Does the glycol reside uniformly within the polymer matrix or does it become enriched at the surface? Is it a homogeneous or heterogeneous distribution? XPS spectra were collected for the various PEDOT samples and the O1s peak was used to quantify the amount of glycol by de-convoluting the peak into its constituent peaks (example given in ref. [45]). Not surprisingly, peak fitting revealed no glycol peak for the sample made without glycol in the oxidant layer, but did show glycol present in increasing amounts for all other samples. Figure 2 shows the level of glycol within the PEDOT film as a function of glycol content within the oxidant layer. As can be seen, the glycol content within the PEDOT film increased until it formed a plateau ( $\approx 16 \mathrm{wt} .-\%)$ at a corresponding glycol content within the oxidant layer of $\approx 48 \mathrm{wt} . \%$. Since XPS measures the approximate top 7-10 nm of a sample[46] the question still remains; is the glycol present only on the surface, or embedded evenly throughout the PEDOT matrix, or distributed in an inhomogeneous manner.

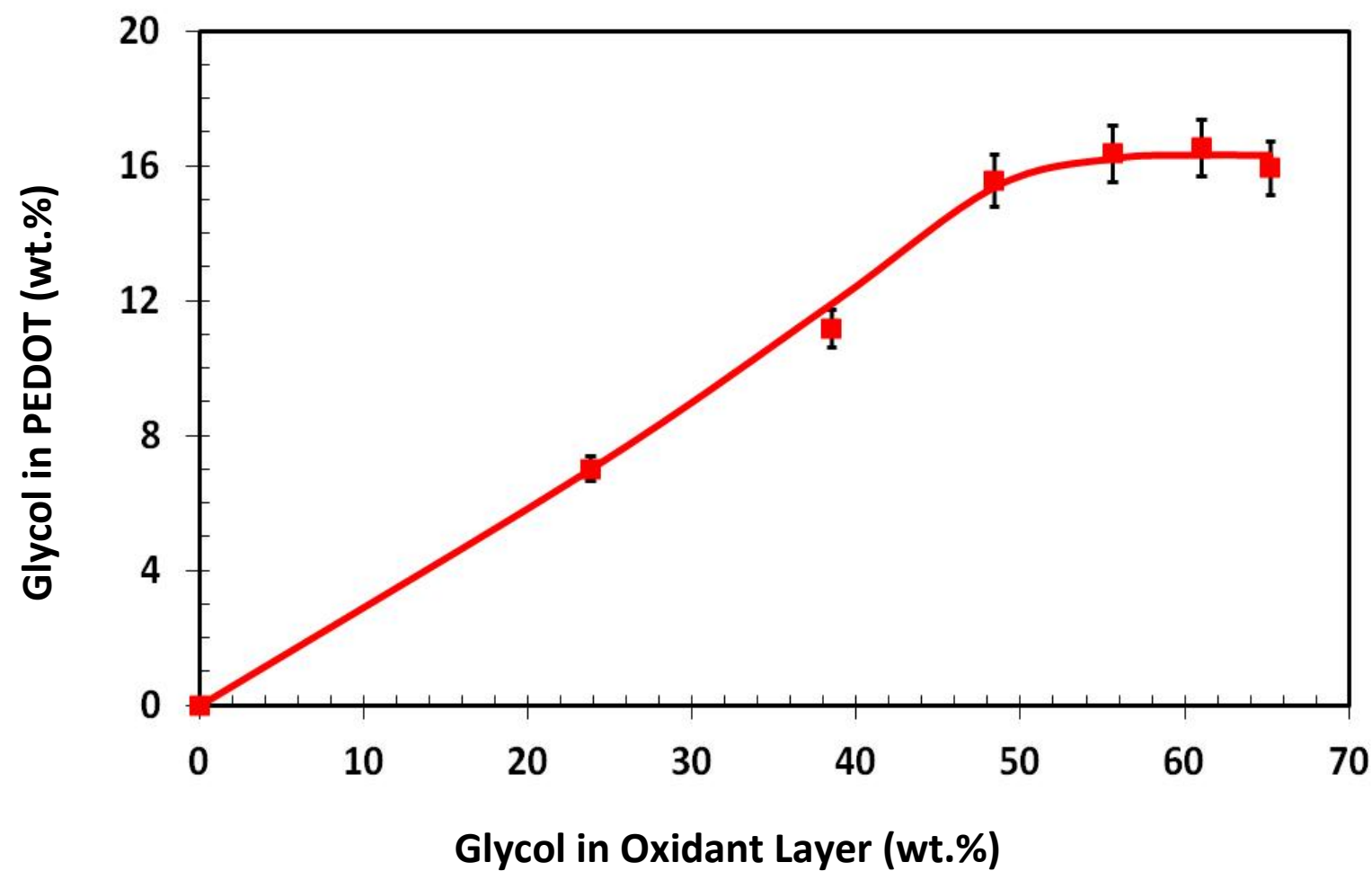


Figure 2. Weight percentage of glycol surfactant within the PEDOT polymer as a function of the glycol content in the oxidant layer.

\subsection{Contact angle measurements}

Contact angle (CA) measurements are extremely sensitive to the energetic state of a surface but unambiguous quantitative analysis requires smooth homogeneous surfaces, whereas our PEDOT samples possess substantial roughness (Fig. 3). Thus, we have used (CA) measurements as a qualitative measure. The results (Table 1) for both advancing, $\theta_{\mathrm{a}}$, and receding, $\theta_{\mathrm{r}}$, contact angles show a general trend downwards with increasing glycol content originally contained within the oxidant layer. This result is at odds with the XPS data which showed that glycol within the PEDOT film reached a plateau of $\approx 16$ wt.-\% at a corresponding 48 wt.-\% glycol within the oxidant layer. Based on the XPS data one would reasonably have expected the same contact angles to be recorded for both 48 and 61 wt.-\% glycol within the oxidant layer, but this was not the case. Separating the effects of physical roughness and chemical heterogeneity is problematic. To resolve the issue, AFM imaging was performed in an effort to obtain physical topography measurements and ToF-SIMS analysis was conducted, as the latter technique provides compositional information at the uppermost surface of a sample (i.e. top 1-2 nm).

Table 1. Advancing, $\theta_{\mathrm{a}}$, and receding, $\theta_{\mathrm{r}}$, contact angles as a function of glycol surfactant within the oxidant layer.

\begin{tabular}{ccc}
\hline $\begin{array}{c}\text { Glycol in Oxidant Layer } \\
(\mathbf{w t . \% )}\end{array}$ & $\begin{array}{c}\text { Contact Angle } \\
\left(\boldsymbol{\theta}_{\mathrm{a}}\right)\end{array}$ & $\begin{array}{c}\text { Contact Angle } \\
\left(\boldsymbol{\theta}_{\mathbf{r}}\right)\end{array}$ \\
\hline 0 & $63 \pm 4$ & $24 \pm 2$ \\
\hline 24 & $61 \pm 2$ & $22 \pm 4$ \\
\hline 48 & $54 \pm 2$ & $21 \pm 4$ \\
\hline 61 & $49 \pm 3$ & $16 \pm 3$ \\
\hline
\end{tabular}




\subsection{AFM analysis}

Figure 3 shows 3D-images and RMS roughness for PEDOT films synthesised with varying amounts of glycol in the oxidant layers. Calculated RMS roughness values were obtained for $1 \mu \mathrm{m}$ and $10 \mu \mathrm{m}$ scans (length scales appropriate to cell size) and are given in Figure 3E. Qualitatively the images show that there is a clear difference between the topography of the PEDOT film without glycol and the films synthesised with glycol. While the topography images of the PEDOT films that have glycol incorporated show a homogenous distribution of roughness over the scan areas of interest, the film without glycol (Fig. 3A) shows an inhomogeneous distribution. This can be seen by comparing the difference in roughness between the $1 \mu \mathrm{m}$ and 10 $\mu \mathrm{m}$ scans where a marked increase in roughness between the two length scales is observed. Within the series of PEDOT films containing glycol, the roughness increased with increasing glycol content, with a maximum roughness of $9.3 \mathrm{~nm}$ recorded for the $61 \mathrm{wt} .-\%$ glycol sample at a scan size of $10 \mu \mathrm{m}$. Interestingly, phase contrast imaging showed no discernible differences at length scales down to $500 \mathrm{~nm}$ indicating that the incorporation of the glycol surfactant within the PEDOT film was either homogeneous and, importantly, at a length scale below that examined (i.e. $<500 \mathrm{~nm}$ ), or that the glycol resided below the top surface layer. To resolve this ToF-SIMS analyses were performed on the PEDOT films. 

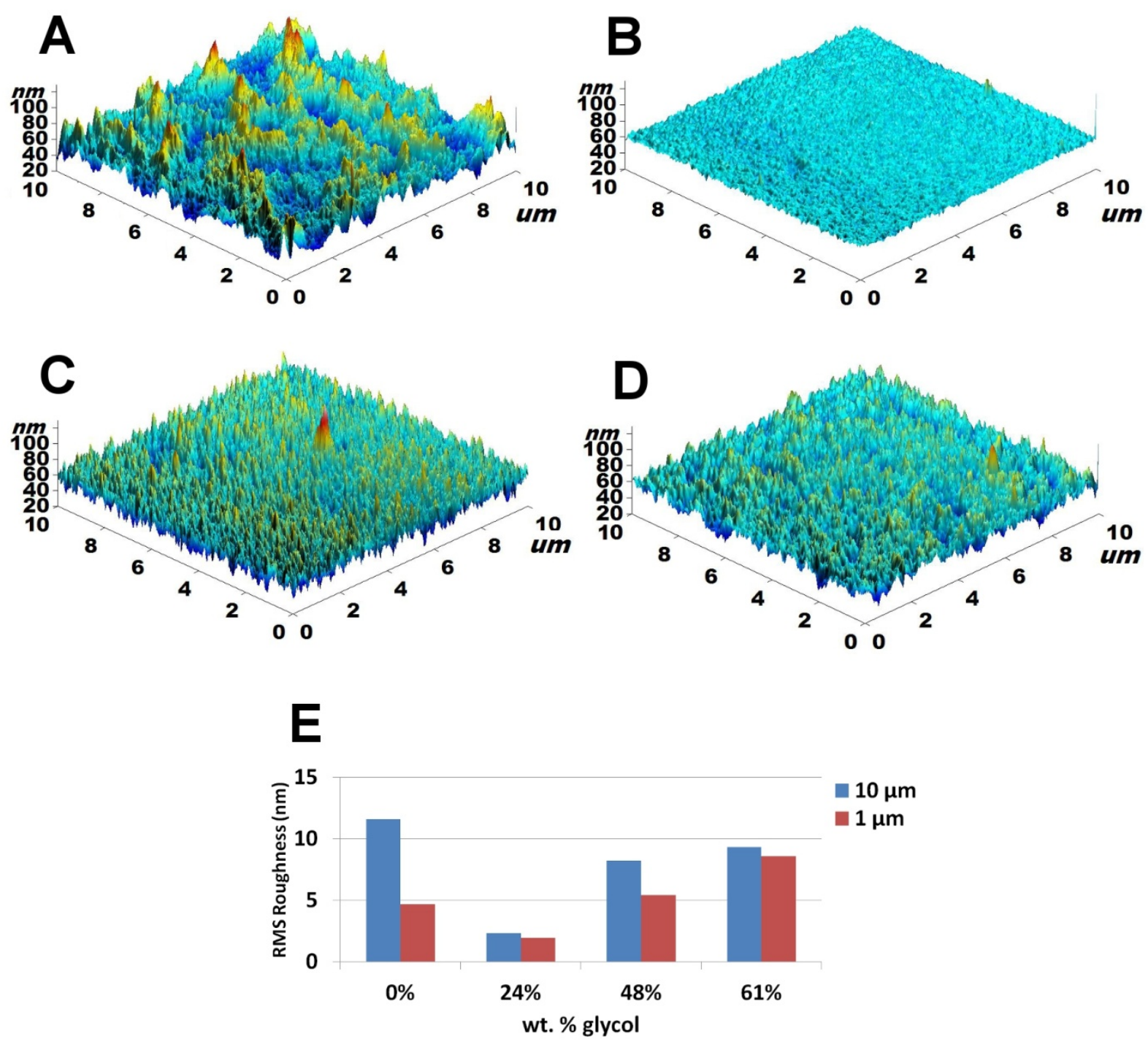

Figure 3. AFM topography images for samples made with: A) $0 \%$; B) 24\%; C) 48\% and; D) $61 \%$ glycol in oxidant layer. E) The RMS roughness measured at length scales of 1 and $10 \mu \mathrm{m}$ (Note: $\mathrm{RMS}_{\text {std dev. }}<10 \%$ relative for all samples and measured scan areas)

\subsection{ToF-SIMS analysis of VPP PEDOT}

Positive ToF-SIMS spectra were analysed to study the extent of changes in surface chemistry with the incorporation of glycol into the PEDOT films. As ToF-SIMS has a high surface sensitivity (ca. 1-2 nm), only the top most surface layer is analysed. This aspect is 
important, as it is the top layer which governs the interactions of proteins and cells with the substrate.

In Figure 4 the normalised counts for major fragment ions assignable to PEG (45 amu) and PPG (59 amu) from the glycol surfactant are shown. The peak intensities were normalised using 126 peaks in each ToF-SIMS spectrum. The data show that both moieties were present on the PEDOT surface, and that their concentration increased as the amount of glycol within the oxidant layer was increased. Small counts were recorded at 45 and 59 amu for 0 wt.-\% glycol due to PEDOT-derived fragment ions with very similar masses to the glycol-derived fragment ions. Since glycol is a high-energy material, a corresponding decrease in the contact angle should result as the concentration increases at the surface of the PEDOT film. Thus, the Tof-SIMS spectra are in qualitative agreement with the contact angle data. The XPS data on the other hand are not in agreement as they show a glycol plateau at $16 \mathrm{wt} .-\%$, yet the contact angle decreased further as glycol within the oxidant layer was increased beyond 48 wt.-\%. Given the fact that XPS measures the first 7-10 nm of a material, compared to ToF-SIMS which measures the top 1$2 \mathrm{~nm}$, one can reconcile the two results by inferring that a glycol-rich surface is formed with a relatively less concentrated region just below, as the glycol within the oxidant layer is increased beyond 48 wt.-\%. This surface enrichment is not measurable by XPS due to its monolayer nature and the modest additional amount on the surface.

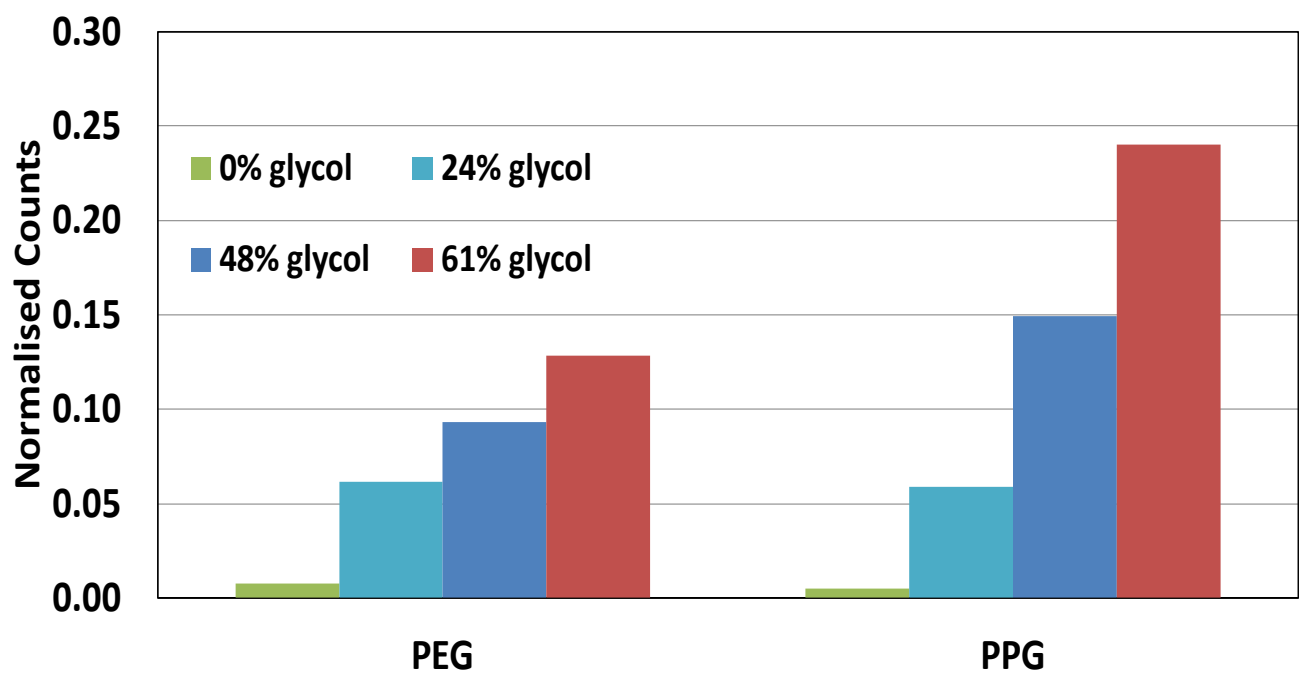


Figure 4. ToF-SIMS relative measurements of the PEG and PPG moieties in the glycol surfactant, which now resides within the PEDOT polymer surface (i.e. top 1-2 nm) for the different glycol weight percents originally in the oxidant layer. $(95 \%$ confidence level with $\mathrm{N}=$ 10 samples)

\subsection{Protein adsorption on VPP PEDOT}

Static PEDOT: The effect of surface characteristics of the VPP PEDOT formulations on protein adsorption was examined by studying the protein adsorption kinetics by QCM. Surface properties including the surface roughness and surface charge can significantly affect the behaviour of proteins at material surfaces, which can in turn influence cell attachment and proliferation at the surface. Fibronectin was chosen as a model serum protein whose adsorption characteristics have been well studied on different surfaces, particularly to understand cell adhesion dynamics at surfaces as it has been shown to be a mediator for cell attachment.[47, 48] AFM measurements were taken prior to commencement of QCM analysis to evaluate relative surface area, allowing comparison of mass adsorption per unit area. The roughness and surface area of the 0 wt.-\% PEDOT film was slightly higher than the other three PEDOT films tested (Fig. 3 and Table 2).

Frequency versus dissipation curves indicated that there was no significant difference in the properties of the adsorbed protein layer, with a single binding event occurring.[47] The viscoelastic properties of the protein layers appeared to be comparable between the three surfaces containing glycol, with the exception being the layer deposited on the PEDOT without glycol (Table 2, $\Delta f / \Delta D$ ) which was slightly stiffer. The conformation of the protein is thus likely to be similar on each surface, which is important as alterations in surface morphology, chemistry or surface charge can cause differences in the viscoelastic properties of the protein layer. These properties indicate a similar water content of the adsorbed protein layer on each surface, allowing comparison between mass adsorbed per unit area for each surface.[47, 49]

The mass of protein adsorbed to each surface was examined as the surface properties of the PEDOT films, particularly the contact angle and ToF-SIMS results suggested that there might 
be significant effects on the adsorption of protein due to the increased level of glycol present (Fig. 4). AFM indicated that no phase segregation was evident on the length scales investigated. The protein adsorption, however, did not appear to be significantly affected by the physical or chemical surface properties (Table 2), indicating that the glycol coverage on all samples was below the density required to significantly reduce protein adsorption.

Table 2. Protein adsorption on PEDOT formed with different amounts of glycol in the oxidant layer as determined by QCM analysis. Surface area was determined from AFM measurements. Mass measurements are the mean of two independent samples and the error indicated is the range of these samples.

\begin{tabular}{cccc}
\hline $\begin{array}{c}\text { Glycol in Oxidant } \\
\text { Layer (wt.\%) }\end{array}$ & $\begin{array}{c}\text { Surface area } \\
\text { (\% increase) }\end{array}$ & $\begin{array}{c}\text { Mass adsorbed } \\
\left(\mathbf{n g} / \mathrm{cm}^{2}\right)\end{array}$ & $\Delta f / \Delta D$ \\
\hline $\mathbf{0}$ & 7.6 & $1319 \pm 137$ & -20.7 \\
$\mathbf{2 4}$ & 0.7 & $1558 \pm 103$ & -15.5 \\
$\mathbf{4 8}$ & 2.8 & $1271 \pm 106$ & -16.1 \\
$\mathbf{6 1}$ & 1.5 & $1539 \pm 62$ & -15.8 \\
\hline
\end{tabular}

Biased PEDOT: Application of charge to the PEDOT surface was examined to determine any direct effect of applied charge on the properties of the protein layer as it adsorbs in situ. The highest conductivity PEDOT formulation (48 wt.-\%) was chosen to investigate the effect of charge application on fibronectin adsorption as this material showed no significant differences in protein behaviour, or cell adhesion or proliferation on its surface compared to TCP or the other PEDOT-glycol formulations tested (refer to next section).

The mass adsorbed to biased surfaces was determined utilising the Voigt model method as previously explained. A general trend is seen with more mass adsorbed to the reduced samples compared with the oxidised samples (Fig. 5). In order to compare the masses directly, the mechanical properties of each layer should be similar. The $\Delta f / \Delta D$ ratio provides an indicator of 
this measurement and shows that the mechanical properties of the fibronectin layers adsorbed to the biased surfaces are indeed different.

Following the application of $+/-100 \mathrm{mV}$ or $+300 \mathrm{mV}$ to the PEDOT substrate, the adsorbed layer of fibronectin did not appear to be significantly mechanically different to the adsorbed layer on the unbiased surface. However the application of higher reducing potential significantly altered the mechanical properties of the fibronectin layer. The $-300 \mathrm{mV}$ reducing potential caused the adsorbing layer to form a denser, less hydrated protein film, as indicated by the significantly higher $\Delta f / \Delta D$ ratio. Whereas the application of an oxidising potential did not alter the $\Delta f / \Delta D$ ratio significantly from the unbiased protein layer properties. These results might suggest a significant difference in protein presentation on biased surfaces[50], particularly at reducing potentials.
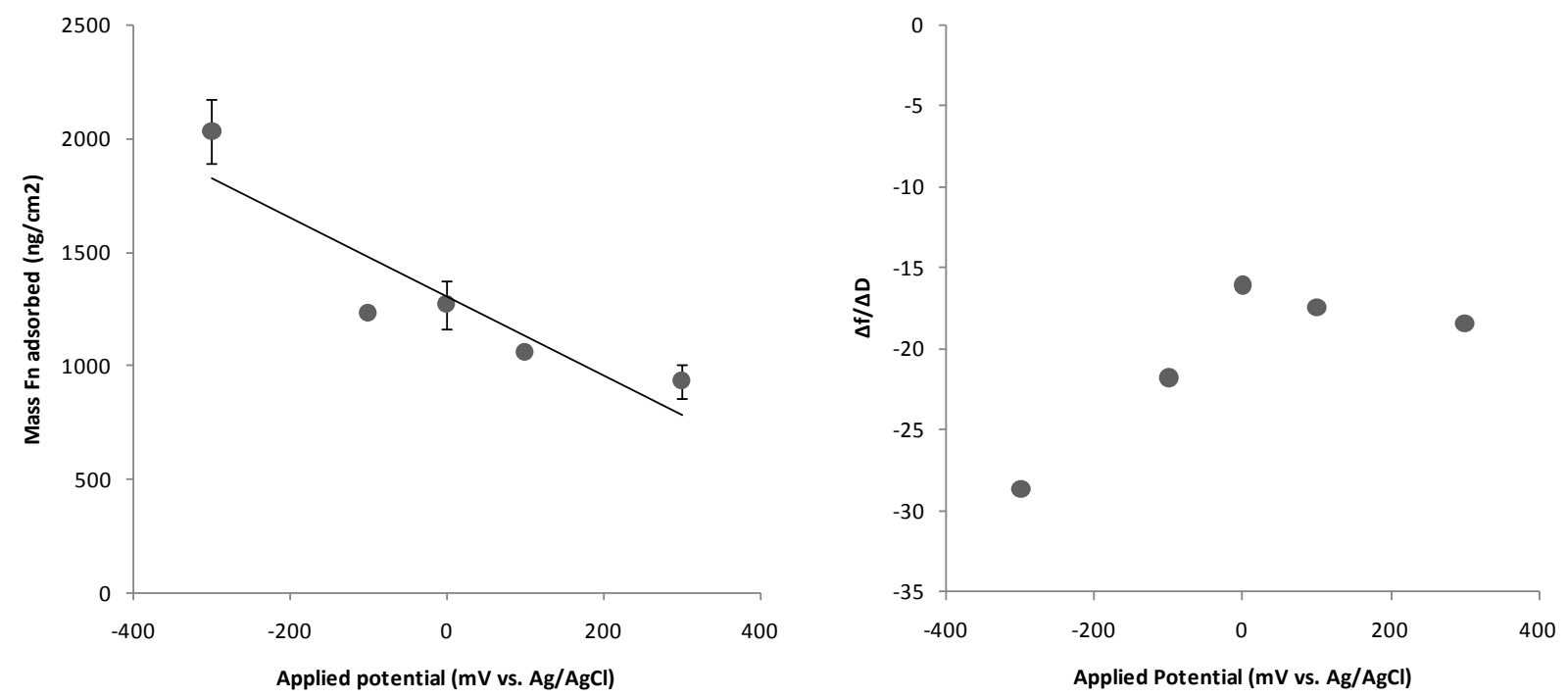

Figure 5. Properties of the fibronectin protein layer adsorbed to the $48 \mathrm{wt}$.-\% PEDOT surface a) Representation of the trending change in adsorbed mass as a function of charge applied. Means represent the average of two samples and error bars represent the range. b) Changes in mechanical properties as a function of charge applied represented by the $\Delta f / \Delta D$ ratio. 


\subsection{Cell adhesion and proliferation on VPP PEDOT}

The following PEDOT samples were selected for cell work: 0, 24, 48 and 61 wt.\% glycol addition. The adhesion of both fibroblast and keratinocyte cell lines was examined following a $2 \mathrm{~h}$ incubation on the surface of the polymers (Fig. 6). Unbound cells were removed by washing and cell numbers quantified. The highest number of fibroblast cells were retained on TCP substrate after $2 \mathrm{~h}$ incubation (Fig. 6a). This number was significantly higher $(\mathrm{p}<0.05)$ than adhesion to any of the PEDOT surfaces. Comparing between the PEDOT surfaces however, there was only a significant difference between the number of cells bound after $2 \mathrm{~h}$ on 0 and $61 \mathrm{wt.} \%$. This indicated that at the extremes of glycol incorporation there is a significant effect on cell adhesion; however, mid-range glycol incorporation does not significantly alter fibroblast cell adhesion. A similar response was seen with keratinocytes, where a significantly higher number of cells $(p<0.05)$ adhered to the TCP surface than to any of the PEDOT surfaces at 2h (Fig. 6b).

Following 48h incubation on the surfaces, the fibroblast population remained at a higher number on the TCP substrate compared to the PEDOT substrates, however, good proliferation was maintained on all surfaces tested. The PEDOT substrates supported the proliferation of fibroblasts regardless of the amount of surface exposed glycol (i.e. surface energy) or the physical roughness. The initial difference in cell adhesion observed at $2 \mathrm{~h}$ did not impact on the proliferation of cells on the PEDOT surface with 0 wt.-\% glycol, with this surface supporting a higher growth rate than the other PEDOT substrates. At $48 \mathrm{~h}$ a significantly higher cell number was reached on the 0 wt.-\% glycol than on 61 wt.-\% glycol surface. The keratinocyte cell line proliferated best on the $48 \mathrm{wt.}$-\% substrate, with a significantly higher cell number reached than on 0 or 61 wt.-\% after $48 \mathrm{~h}$. The 0 wt.-\% PEDOT material supported the lowest proliferation rate, significantly below that on TCP, 24 and 48 wt.-\%.

Taken together, these results suggest that the cell behaviour on these surfaces is cell line dependent, with 0 wt.-\% supporting the lowest adhesion but highest proliferation rate of fibroblasts, and the lowest adhesion and proliferation rate of keratinocytes. The $0 \mathrm{wt.}-\%$ glycol substrate supported the lowest cell adhesion after $2 \mathrm{~h}$ compared to the glycol composite PEDOT surfaces. This was contrary to speculation that the surface presence of glycol would inhibit this 
binding event. Based on these results, it is likely that there are other physicochemical factors acting on the cell adhesion and proliferation kinetics.
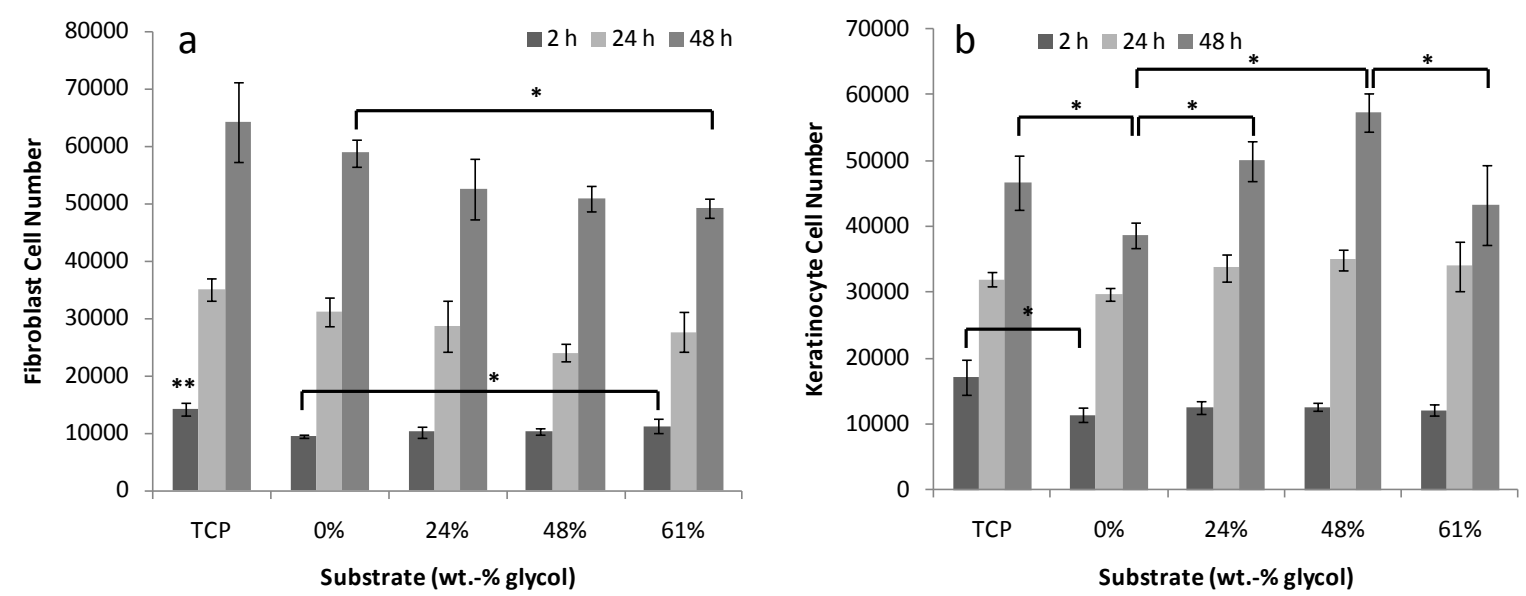

Figure 6: Cell adhesion and proliferation data of a) 3T3 fibroblasts and b) HaCaT keratinocytes on PEDOT substrates over $48 \mathrm{~h}$. Means are averages of 4 replicates and error bars are standard error. * indicates significant difference between indicated measurements, ** indicates difference from all other measurements at the same time point.

\subsection{Cell morphology on VPP PEDOT}

Static PEDOT: The morphology of cells grown on the different polymers was visualised by staining the F-actin filaments of the cytoskeleton. Cells were imaged following $72 \mathrm{~h}$ incubation on each surface and the morphology of the two cell types were compared to cells seeded onto the control TCP surface. There were no distinct differences observed between the different polymers tested with cells displaying similar morphology to those cultured on the TCP substrate, and with cell densities slightly higher on the TCP substrate compared to the PEDOT substrates (data not shown). This correlated well with the small differences seen in the cell proliferation studies.

Biased PEDOT: $\quad$ Cell viability and morphology was visualised using Calcein AM cell permanent dye following $12 \mathrm{~h}$ incubation on biased surfaces. Keratinocytes (Fig. 7 a-c) and fibroblasts (Fig. 7 d-f) each appear of similar morphology on biased and unbiased surfaces. The graph in Figure 7 shows analysis of average cell area per cell body on each treated surface for 
keratinocytes (Fig. 7g) and fibroblasts (Fig. 7h). Statistical analysis shows that keratinocytes spread significantly better on reduced 48 wt.-\% PEDOT $(\mathrm{p} \leq 0.05)$ while fibroblasts spread significantly worse on oxidised $48 \mathrm{wt} . \mathrm{\%}$ PEDOT $(\mathrm{p} \leq 0.05)$. As the presentation of protein at the surface is similar under similar treatment, these results indicate that the adhesion of cells to these treated surfaces is cell type dependent.
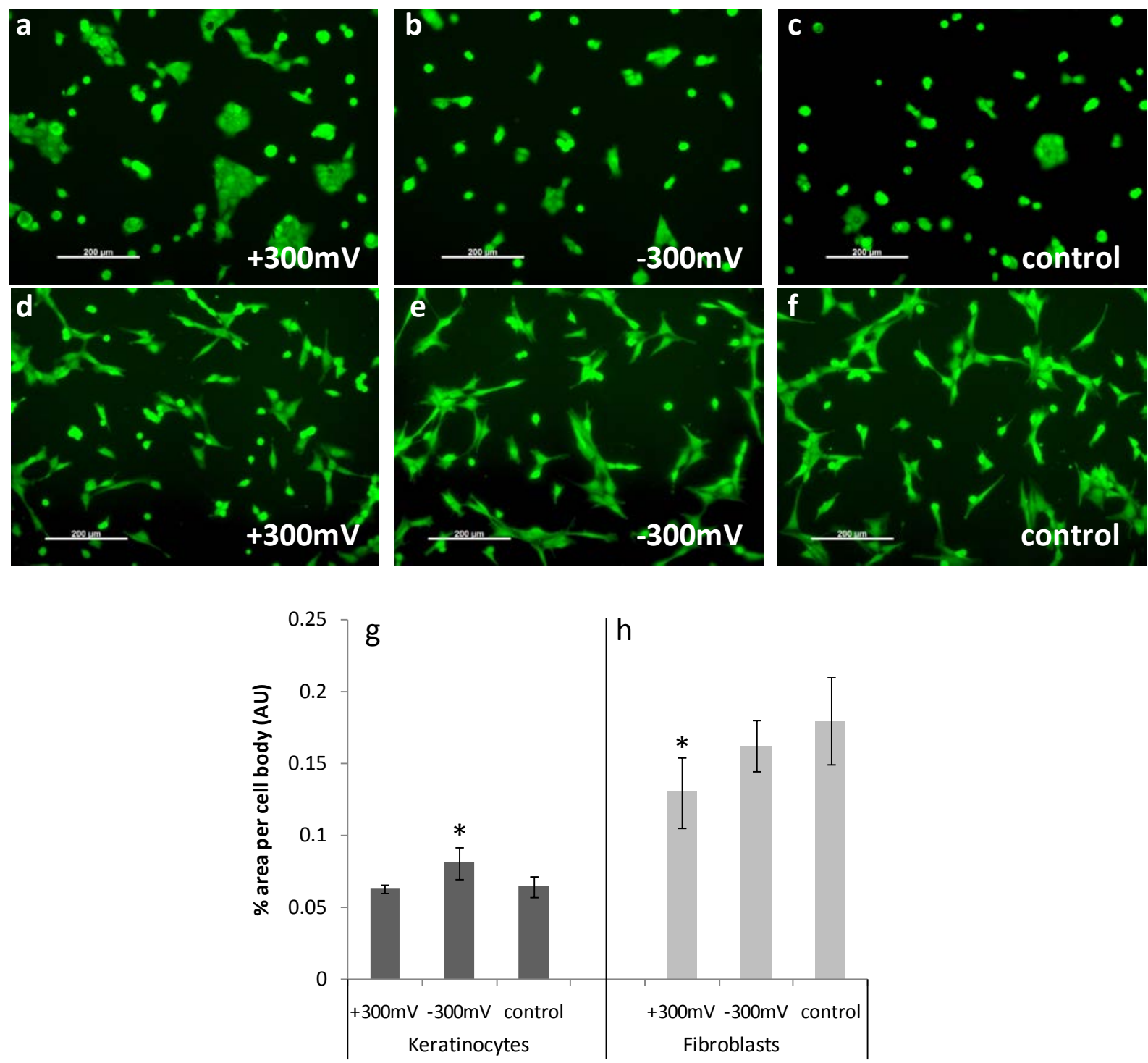

Figure 7. Calcein stained images of live cells on PEDOT 48 wt.-\% glycol which were biased prior to incubation with complete media, followed by cell seeding. Keratinocytes on variously charged surfaces (as indicated on image) are shown in a) to c); with fibroblasts shown in d) to f). Graphs shown in g) and h) show relative \% area per cell body for each cell type. Means are averages of $>6$ analysed images with error bars indicating the standard error of the mean. * indicates significant difference to other measurements within the group. 


\section{Discussion}

\subsection{Physical aspects of VPP PEDOT polymers}

Ex vivo tissue engineering offers a long term adjunct to conventional cell replacement methodologies, such as donor transplants or grafting, for the repair or replacement of damaged tissue. Within the context of materials engineering, the ability to successfully create an artificial environment conducive to desired cell proliferation will depend on the characteristics that can be tailored into the candidate host materials. Of the many possibilities, conducting polymers have shown considerable potential and, as such, have received significant attention in the bio-materials literature. The ability to alter the physical, chemical and electrical properties of these polymers opens the door to a vast array of possibilities. The focus of this study was to investigate whether VPP PEDOT could be used as a host substrate that would support in vitro studies, with the longer term goal of also using the polymer as the electrode in electro-stimulation studies.

The synthesis of high conductivity PEDOT can be accomplished using several facile methods, of which one is VPP. One of the easiest and most reproducible methodologies employs the surfactant glycol to moderate the polymerisation rate, resulting in high conductivity PEDOT. This comes at a cost, however, as the use of glycol results in the formation of a PEDOT-glycol composite material. There are numerous studies reporting that the addition of glycol onto substrate surfaces has an adverse or inhibiting effect on the adhesion and proliferation of different cell lines. To this end a systematic study was conducted to ascertain the presence of glycol on the surface of VPP PEDOT, and whether it was at a surface density that would be problematic.

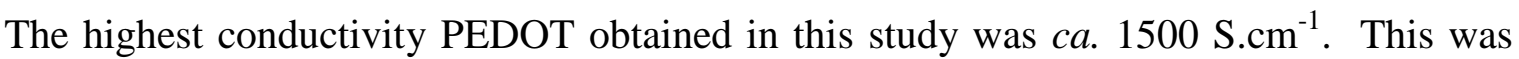
achieved using an oxidant layer loading of 48 wt.-\% glycol, which produced a PEDOT polymer composite with 16 wt.-\% (refer Fig. 2) glycol. Increasing the glycol loading within the oxidant layer did not result in any additional glycol being present in the PEDOT according to XPS data. Interestingly, however, the advancing and receding contact angles decreased further when the glycol loading in the oxidant layer was increased to 61 wt.-\%, even though XPS data indicated that the level of glycol had reached a plateau. XPS is able to measure down to a depth of approximately 7-10 nm, and so cannot be considered a true surface sensitive technique. To 
elucidate this apparent conflict ToF-SIMS was utilised, as the penetration depth is only of the order of 1-2 nm. The results (Fig. 4) showed that the topmost layer did indeed contain more glycol, even though XPS had indicated that the total glycol content had reached a plateau of 16 wt.-\%. The XPS and ToF-SIMS results can be reconciled by suggesting that there is surface enrichment of glycol after the PEDOT matrix becomes saturated with glycol. Such a conclusion is supported by the contact angle data which showed a monotonic decrease in both advancing and receding angles. Given that there is a significant level of glycol present on the surface of the PEDOT film, AFM phase contrast imaging was employed to examine the glycol presentation at the surface. The technique however was unable to detect any phase changes at the length scales measured (i.e. 1 and $10 \mu \mathrm{m}$ ). The result indicates that the incorporation of glycol within the PEDOT composite is at a length scale well below the typical dimensions of the cell lines used in this study. Such a result suggests that the impact of glycol within the PEDOT polymer may be minimal in nature, and this aspect is discussed in the following section.

\subsection{Biological aspects of VPP PEDOT substrates}

Glycol is well known for its antifouling capability, and for its non-toxic and nonimmunogenic behaviour. Its inclusion in biomaterial formulations is generally to inhibit interaction with proteins though it is also exploited for its mechanical properties. The PEDOT glycol composites examined in this study were prepared to exploit the high conductivity of the material. This desirable property as well as the good biocompatibility of PEDOT deems the material a good candidate for applying stimulus to cells and tissues. Protein adsorption is a good indicator of cell interactions at a surface, as cell adhesion is mediated by certain proteins. Fibronectin was examined as a model serum protein involved in the adhesion of many cell types. The interactions of fibronectin at the surface of each material was examined by QCM and indicated that there was a single binding event occurring to form the adsorbed protein layer. Similar properties observed on each PEDOT glycol composite surface despite the significantly different amounts of exposed glycol moieties at the material surfaces. The 0 wt.-\% PEDOT surface was significantly rougher and displayed a slightly stiffer protein layer. The mass of protein adsorbed on the surfaces per unit area showed slight variations with 24 and 61 wt.-\% adsorbing slightly higher amounts of protein than 0 and 48 wt.-\% PEDOT, however these differences were not significant. These observations did not correlate with surface energy or 
exposed glycol, indicating that there may be other contributing physicochemical factors which impact on protein adsorption.

The properties of the cell interactions with the PEDOT materials were then examined to determine any correlations with observed glycol content or protein behaviour. Initial adhesion of both cell types examined was lowest on the rough 0 wt.-\% PEDOT surface, though this surface showed slightly higher adsorption of protein mass, indicating a possible role of surface topography on cell adhesion. Following initial adhesion however, each cell type behaved slightly differently on the surfaces, with fibroblasts proliferating best on 0 wt.-\% PEDOT, even though initial adhesion was low, and keratinocytes proliferating best on 48 wt.-\% PEDOT. Effects of glycol at the surface on the cell morphology also appeared to be insignificant with cells on PEDOT retaining a similar morphology to those on TCP at comparable time points.

Taken together, these high conductivity PEDOT surfaces with different amounts of surface exposed glycol appear to provide good support for cell adhesion and proliferation. These results indicate their suitability for further investigation into the delivery of electrical stimulus via the materials in the development of biomedical devices.

Examination of the effect of the application of charge to a material on protein interactions occurring at its surface provides insights into how a material will interact with cells and tissues in vivo. This study has shown that highly conductive PEDOT glycol composites are certainly compatible with different cell types. Charge application altered the surfaces in such a way that they interacted with the model protein tested here, fibronectin, in a manner dependent on the level of potential applied, and whether the material was pushed toward a reducing or oxidising potential. Oxidised PEDOT adsorbed less protein onto its surface, however the mechanical properties of the protein layer were maintained similar to unbiased PEDOT. This correlated with significantly less area covered by fibroblast cells, indicating lower adhesive properties of this protein coated surface. Reduced PEDOT however, while it demonstrated higher mass adsorption to its surface, also displayed altered mechanical properties of this adsorbed layer. This alteration towards a denser, less hydrated protein layer with increased reducing potential in turn altered the adhesion of keratinocytes, with these cells displaying more area covered per cell on this surface. The difference in cell spreading of the cell types tested indicate a difference in dependence on protein presentation vs. protein density at material surfaces between the two cell types. 


\section{Conclusions}

High conductivity PEDOT glycol composites display conductivities only one order of magnitude lower than some metals and alloys. This desirable property combined with its demonstrated ability to support the adhesion and proliferation of a number of cell types indicate this material to be a useful alternative to current metal technologies for implantable devices. An examination into the effect of biasing the PEDOT surface by the application of oxidising or reducing potentials revealed significant effects on the protein layer adsorbed at the surface, and hence cell-type dependent behaviour at the surface. This observed difference opens up the possibility of tuning PEDOT surfaces by the application of potential to alter cell behaviour at the material interface by influencing the mediating protein layer.

\section{Acknowledgements}

The authors acknowledge Miss Amy Gelmi for assistance with AFM imaging. The authors gratefully acknowledge the Australian Research Council for funding. 


\section{References}

1. Nardes A, Kemerink M, de Kok MM, Vinkin E, Maturova K, and Janssen R. Conductivity, work function, and environmental stability of pedot:Pss thin films treated with sorbitol. Org Electron 2008;9:727-734.

2. $\quad$ Ouyang J, Chu C-W, Chen F-C, Xu Q, and Yang Y. High conductivity poly(3,4ethylenedioxythiophene):Poly(styrenesulfonate) film and its application in polymer optoelectronic devices. Adv Funct Mater 2005;15:203-208.

3. Winther-Jensen B and Krebs F. High-conductivity large area semi-transparent electrodes for polymer photovoltaics by silk screen printing and vapour-phase deposition. Sol Energ Mat Sol C 2006;90:123-132.

4. Winther-Jensen B and West K. Stability of highly conductive poly-3,4-ethylenedioxythiophene. React Funct Polym 2006;66:479-483.

5. Zhang F, Johansson M, Andersson MR, Hummelen JC, and Inganas O. Polymer photovoltaic cells with conducting polymer anodes. Adv Mater 2002;14:662-665.

6. Wu W, Liu Y, Wang Y, Xi H, Gao X, Di C, et al. High performance, low operating voltage organic field effect transistors with low pinch off voltages. Adv Funct Mater 2008;18:810815.

7. Senthilkumar N, Kang H, Park D, and Choe Y. Improving efficiency of organic photovoltaic cells using pedot:Pss and mwcnt nanocomposites as a hole conducting layer. $\mathrm{J}$ Macromol Sci A 2010;47:484-490.

8. Bernards D, Macaya D, Nikolou M, DeFranco J, Takamatsu S, and Malliaras G. Enzymatic sensing with organic electrochemical transistors. J Mater Chem 2007;18:116-120.

9. Stevens MM and George JH. Exploring and engineering the cell surface interface. Science 2005;310:1135-1138.

10. Discher DE, Janmey P, and Wang Y-l. Tissue cells feel and respond to the stiffness of their substrate. Science 2005;310:1139-1143.

11. Griffith LG. Emerging design principles in biomaterials and scaffolds for tissue engineering. Ann NY Acad Sci 2002;961:83-95.

12. Huang J, Miller P, Wilson J, de Mello A, de Mello J, and Bradley DDC. Investigation of the effects of doping and post-deposition treatments on the conductivity, morphology, and work function of poly(3,4-ethylenedioxythiophene)/poly(styrene sulfonate) films. Adv Funct Mater 2005;15:290-296. 
13. Gürsel A, Alkan S, Toppare L, and Yağcı Y. Immobilization of invertase and glucose oxidase in conducting h-type polysiloxane/polypyrrole block copolymers. React Funct Polym 2003;57:57-65.

14. Niu L, Kvarnstrom C, Froberg K, and Ivaska A. Electrochremically controlled surface morphology and crystallinity in poly(3,4-ethylenedioxythiophene) films. Synthetic Met 2001;122:425-429.

15. Gelmi A, Higgins M, and Wallace G. Physical surface and electromechanical properties of doped polypyrrole biomaterials. Biomaterials 2010;31:1974-1983.

16. Bai H, Li C, Chen F, and Shi G. Aligned three-dimensional microstructures of conducting polymer composites. Polymer 2007;48:5259-5267.

17. Saltó C, Saindon E, Bolin M, Kanciurzewska A, Fahlman M, Jager EWH, et al. Control of neural stem cell adhesion and density by an electronic polymer surface switch. Langmuir 2008;24:14133-14138.

18. Svennersten K, Bolin MH, Jager EWH, Berggren M, and Richter-Dahlfors A. Electrochemical modulation of epithelia formation using conducting polymers. Biomaterials 2009;30:6257-6264.

19. Anselme K, Linez P, Bigerelle M, Le Maguer D, Le Maguer A, Hardouin P, et al. The relative influence of the topography and chemistry of tial6v4 surfaces on osteoblastic cell behaviour. Biomaterials 2000;21:1567-1577.

20. Green RA, Lovell NH, Wallace GG, and Poole-Warren LA. Conducting polymers for neural interfaces: Challenges in developing an effective long-term implant. Biomaterials 2008;29:3393-3399.

21. Quigley A, Razal J, Thompson B, Moulton S, Kita M, Kennedy E, et al. A conductingpolymer platform with biodegradable fibers for stimulation and guidance of axonal growth. Adv Mater 2009;21:4393-4397.

22. Aaron $\mathrm{R}$ and Ciombor $\mathrm{D}$. Therapeutic effects of electromagnetic fields in the stimulation of connective tissue repair. J Cell Biochem 1993;52:42-46.

23. Wong J, Langer R, and Ingber D. Electrically conducting polymers can noninvasively control the shape and growth of mammalian cells. P Natl Acad Sci USA 1994;91:32013204.

24. Ciombor D and Aaron R. Influence of electromagnetic fields on endochronal bone formation. J Cell Biochem 1993;52:37-41.

25. Rowlands A and Cooper-White J. Directing phenotype of vascular smooth muscle cells using electrically stimulated conducting polymers. Biomaterials 2008;29:4510-4520. 
26. Gilmore K, Kita M, Han Y, Gelmi A, Higgins M, Moulton S, et al. Skeletal muscle cell proliferation and differentiation on polypyrrole substrates doped with extracellular matrix components. Biomaterials 2009;30:5292-5304.

27. Meng S, Rouabhia M, Shi G, and Zhang Z. Heparin dopant increases the electrical stability, cell adhesion, and growth of conducting polypyrrole/poly(l,l-lactide) composite. J Biomed Mater Res A 2008;87A:332-344.

28. Razal J, Kita M, Quigley A, Kennedy E, Moulton S, Kapsa M, et al. Wet-spun biodegradable fibers on conducting platforms: Novel architectures for muscle regeneration. Adv Funct Mater 2009;19:3381-3388.

29. Richardson-Burns S, Henricks J, Foster B, LK P, Kim D-H, and Martin D. Polymerization of the conducting polymer poly(3,4-ethylenedioxythiophene) (pedot) around living neural cells. Biomaterials 2007;28:1539-1552.

30. Green R, Lovell N, and Poole-Warren L. Impact of co-incorporating laminin peptide dopants and neurotrophic growth factors on conducting polymer properties. Acta Biomater 2010;6:63-71.

31. Fabretto M, Autere J-P, Hoglinger D, Field S, and Murphy P. Vacuum vapour phase polymerised poly(3,4-ethylenedioxythiophene) thin films for use in large scale electrochromic devices. Thin Solid Films 2011;519:2544-2549.

32. Fabretto M, Jariego-Moncunill C, Autere J-P, Michelmore A, Short R, and Murphy P. High conductivity pedot resulting from glycol/oxidant complex and glycol/polymer intercalation during vacuum vapour phase polymerisation. Polymer 2011;52:1725-1730.

33. Winther-Jensen B and West K. Vapour-phase polymerizaion of 3,4ethylenedioxythiophene: A route to highly conducting polymer surface layers. Macromolecules 2004;37:4538-4543.

34. Fabretto M, Zuber K, Hall C, Murphy P, and Griesser H. The role of water in the synthesis and performace of vapour phase polymerised pedot electrochromic devices. J Mater Chem 2009;19:7871-7878.

35. Wischerhoff E, Uhlig K, Lankenau A, Borner H, Laschewsky A, Duschl C, et al. Controlled cell adhesion on peg-based switchable surfaces. Angew Chem Int Edit 2008;47:5666-5668.

36. Tziampazis E, Kohm J, and Moghe P. Peg-varient biomaterials as selectively adhesive protein templates: Model surfaces for controlled cell adhesion and migration. Biomaterials 2000;21:511-520.

37. Satomi T, Nagasaki Y, Kobayashi H, Tateishi T, Kataoki K, and Otsuka H. Physicochemical characterization of densley packed poly(ethylene glycol) layer for minimizing nonspecific protein adsorption. J Nanosci Nanotechno 2007;7:2394-2399. 
38. Jeon S, Lee J, Andrade J, and De Gennes P. Protein-surface interactions in the presence of polyethylene oxide i. Simplified theory J Colloid Interf Sci 1991;142:149-158.

39. Michel R, Pasche S, Textor M, and Castner D. Influence of peg architecture on protein adsorption and conformation. Langmuir 2005;21:12327-12332.

40. Ekblad T, Faxalv L, Andersson O, Wallmark N, Larsson A, Lindahl T, et al. Patterned hydrogels for controlled platelet adhesion from whole blood and plasma. Adv Funct Mater 2010;20:2396-2403.

41. Uhlig K, Wischerhoff E, Lutz J-F, Laschewsky A, Jaeger M, Lankenau A, et al. Monitoring cell detachment on peg-based thermoresponsive surfaces using tifr microscopy. Soft Matter 2010;6:4262-4267.

42. Stalder A, Kulik G, Sage D, Barbieri L, and Hoffmann P. A snake-based approach to accurate determination of both contact points and contact angles. Colloid Surface A 2006;286:92-103.

43. Cogan SF. Neural stimulation and recording electrodes. Annu Rev Biomed Eng 2008;10:275-309.

44. He L, Lin D, Wang Y, Xiao Y, and Che J. Electroactive swnt/pegda hybrid hydrogel coating for bio-electrode interface. Colloid Surface B 2011.

45. Evans D, Fabretto M, Mueller M, Zuber K, Short R, and Murphy P. Vacuum vapor phase polymerization of highly conductive pedot incorporating self healing nano-structured oxidant films. Marcomol Rapid Comm 2011;submitted.

46. Briggs D, Surface analysis of polymers by xps and static sims. 1998, Cambridge, NY: Cambridge University Press.

47. Höök F, Rodahl M, Brzezinski P, and Kasemo B. Energy dissipation kinetics for protein and antibody-antigen adsorption under shear oscillation on a quartz crystal microbalance. Langmuir 1998;14:729 - 734.

48. García AJ, Vega MD, and Boettiger D. Modulation of cell proliferation and differentiation through substrate-dependent changes in fibronectin conformation. Mol Biol Cell 1999;10:785-798.

49. Hovgaard MB, Rechendorff K, Chevallier J, Foss M, and Besenbacher F. Fibronectin adsorption on tantalum: The influence of nanoroughness. J Phys Chem B 2008;112:8241 8249.

50. Molino PJ, Higgins MJ, Innis PC, Kapsa RMI, and Wallace GG. Fibronectin and bovine serum albumin adsorption and conformational dynamics on inherently conducting polymers: A qcm-d study. Langmuir 2012;10.1021/la300692y. 